\title{
A pH-Responsive Multifunctional Nanocarrier in the Application of Chemo-Photodynamic Therapy
}

\author{
Xiaohong Hu $\mathbb{D}^{1},{ }^{1}$ Ziyu Gao, ${ }^{1}$ Huaping Tan $\mathbb{D},{ }^{2}$ and Long Zhang ${ }^{1}$ \\ ${ }^{1}$ School of Material Engineering, Jinling Institute of Technology, Nanjing 211169, China \\ ${ }^{2}$ Biomaterials for Organogenesis Laboratory, School of Materials Science and Engineering, Nanjing University of Science \\ and Technology, Nanjing 210094, China
}

Correspondence should be addressed to Xiaohong Hu; hxh@jit.edu.cn

Received 10 November 2018; Revised 21 December 2018; Accepted 14 January 2019; Published 27 February 2019

Academic Editor: Ruibing Wang

Copyright (c) 2019 Xiaohong Hu et al. This is an open access article distributed under the Creative Commons Attribution License, which permits unrestricted use, distribution, and reproduction in any medium, provided the original work is properly cited.

In cancer therapy, combined utilization of anticancer drug and photosensitizer attracts increasing interest due to enhanced curative effects and reduced side effects. Since the drug delivery system is an effective method to enhance curative effects, drug carriers for codelivery of the two abovementioned molecules are essentially important for chemophotodynamic therapy. Based on the foundation, a nanocarrier with $\mathrm{pH}$-responsive and targeted properties was designed, prepared, and researched in the work. A $\mathrm{pH}$-sensitive nanoparticle was fabricated by acetylated $\beta$-cyclodextrin (Ac- $\beta$-CD) using oil-in-water $(\mathrm{O} / \mathrm{W})$ emulsion technique. During the fabrication processing, a functional emulgator (gelation-folic acid ester (G-FA)) with a biorecognition domain was absorbed onto the surface of the nanoparticle, which endowed a nanoparticle-targeted property. The nanoparticle exhibited a coarse surface, $\mathrm{pH}$-responsive property, and similar fluorescence characteristic as G-FA. The cell endocytosis profile revealed that equilibrium endocytosis could be reached after being cocultured with $1.0 \mathrm{mg} / \mathrm{mL}$ nanoparticle for $8 \mathrm{~h}$. Furthermore, camptothecin (CPT) as an anticancer drug and phthalocyanine (PcZn) as a photosensitizer were encapsulated into the nanoparticle during the fabrication processing. The nanoparticle enhanced the fluorescence effects of PcZn on water solution, and CPT encapsulation proportion was slightly influenced by initial CPT concentration. The $\mathrm{pH}$ value influenced the PcZn fluorescence behavior and CPT release behavior of the nanoparticle. In vitro cytoviability evaluation confirmed the therapeutic effect of the nanocarrier on HEP2 cells. Finally, the results of preliminary in vivo evaluation revealed that the reported nanocarrier in the research could inhibit cancer development with little effects on the body weight of mice.

\section{Introduction}

Photodynamic therapy (PDT) combined with chemotherapy for cancer treatment has been intensively concerned on account of their enhanced curative effect and lesser side effects [1-5]. In PDT, a photosensitizer, which is an essential chemical, can obtain enough energy from laser and convert it to heat that induces cancer cell apoptosis and death [6]. However, most photosensitizers had slight solubility and tend to agglomerate into dimer in water, which leads to loss of photosensitive characteristic and thus hinder the curative effect of PDT. In the other aspect, some anticancer drug in chemical therapy has also some disadvantage of severe side effect due to large toxicity and reduced curative effect due to limited water solubility [6-11]. Therefore, an effective and efficient carrier for codelivery of anticancer drug and photosensitizer is a premise to realize the combined therapy $[9,10]$. Recently, Zhang et al. developed a nanoscale drug delivery system (nDDS) for codelivery of cisplatin prodrug and chlorin e6 (Ce6), which exhibited potent anticancer activity against A549R cells [12]. Additionally, the Ce6- and doxorubicin- (Dox-) loaded pegylated graphene oxide (pGO) nanophysisorplexes (Ce6/Dox/pGO) were reported to have synergistic curative effects [13]. Based on these 
foundations, a nanoparticle drug delivery system for codelivery of anticancer drug (camptothecin (CPT)) and photosensitizer (phthalocyanine (PcZn)) was designed, fabricated, and evaluated in the research, which is aimed at providing an effective and efficient nanocarrier for chemo-photodynamic therapy.

On account of a lower $\mathrm{pH}$ value environment in tumor tissue, low $\mathrm{pH}$-triggered carriers can respond to acid environment and control drug release at the tumor site, which have attracted intense attention in the field of drug delivery $[8,14-18]$. Furthermore, biocompatibility and biodegradation are essential prerequisites for materials in their biomedical application. Although a lot of synthesized $\mathrm{pH}$-sensitive polymers have been used to prepare $\mathrm{pH}$-sensitive carriers, the biodegradation of these polymers is not easy to realize and the biocompatibility of these polymers including their degradation products is also a problem. In consideration of biocompatibility and biodegradation, natural materials like polysaccharides and proteins are optimal choices to fabricate all kinds of carriers on account of natural biodegradation and excellent biocompatibility [19-26]. Therefore, $\mathrm{pH}$-sensitive natural polysaccharides have been designed and synthesized through reversible acetylation, which also endow materialhydrophobic groups [27-33]. The hydrophilic-lipophilic characteristic of polysaccharides is simultaneously altered by acetylation, which benefits the $\mathrm{O} / \mathrm{W}$ emulsion method for nanoparticle fabrication. The $\mathrm{pH}$ response property of acetylated materials is attributed to the transition of undissolvable hydrophobic acetal groups to dissolvable hydrophilic hydroxy groups in $\mathrm{pH} 5.5$ aqueous solution [27-33]. In our previous work, $\mathrm{pH}$-sensitive $\beta$-cyclodextrin $(\beta$-CD) was synthesized and investigated concerning the effects of reaction condition on $\mathrm{pH}$ responsiveness and stability [33]. In a further step, a biocompatible and $\mathrm{pH}$-responsive $\beta$-CD nanoparticle was obtained and studied in view of synthesis parameters, $\mathrm{pH}$ response property, and biocompatibility [33].

Besides fundamental biocompatibility and special response properties, accurate orientation to targeted cells or tissue for nanocarriers is a proven measure for effective and efficient drug delivery [34-37]. Therefore, an additional targeting design for nanoparticle is a feasible choice to optimize nanocarriers for drug and photosensitizer codelivery. Herein, a targeted pH-responsive nanoparticle was designed and prepared for codelivery of anticancer drug and photosensitizer in the work. The active targeting based on biological recognition and passive targeting based on magnetic interaction are frequently used methods to design targeting properties for the nanoparticle [34-38]. It has been reported that folic acid and folic acid receptors are a pair of ubiquitous biological recognition in both human tissue and tumor [39-41]. Nevertheless, either the number or activity of folic acid receptors in tumor is higher than that in normal tissue. Moreover, folic acid itself has good structural stability, low immunogenicity, and good biocompatibility, which becomes an ideal targeting molecule [39-41]. Therefore, folic acid was modified on the surface of a nanoparticle during the fabrication process in the research. At the same time, camptothecin (CPT) as a model anticancer drug and zinc phthalocyanine $(\mathrm{PcZn})$ as a model photosensitizer were encapsulated into the nanoparticle during the fabrication process. Finally, in vitro and preliminary in vivo investigations were conducted to evaluate the nanocarrier.

\section{Experimental Section}

2.1. Materials. Gelatin, folic acid (FA), $\beta$-cyclodextrin $(\beta$-CD), 2-methoxypropene, pyridinium 4-toluenesulfonate, zinc phthalocyanine (PcZn), anhydrous dimethyl sulfoxide (DMSO), and dichloromethane (DCM) were purchased from Shanghai Medicine and Chemical Company, China. N,N-Dicyclohexylcarbodiimide (DCC) and N-hydroxysuccinimide (NHS) were obtained from Shanghai Energy Chemical Company Limited. Camptothecin (CPT), dialysis tube $\left(M_{w}\right.$ : 8000-14000), 3-(4,5-dimethyl) thiazol-2-yl-2,5-dimethyl tetrazolium bromide (MTT), trypsin, rhodamine $\mathrm{B}$ isothiocyanate (RBITC), 4',6-diamidino-2-phenylindole (DAPI), and Dulbecco's minimum essential medium (DMEM) were obtained from Sigma. Antifade mounting medium and fetal bovine serum (FBS) were purchased from Beyotime Biotech. Co., China. All other reagents and solvents were of analytical grade and used as received.

2.2. Synthesis and Characterization of G-FA. $0.441 \mathrm{~g}$ FA was dissolved in anhydrous DMSO, into which $0.404 \mathrm{~g}$ DCC and $0.229 \mathrm{~g}$ NHS were sequentially added. After the reaction had lasted for $12 \mathrm{~h}$ at $30^{\circ} \mathrm{C}$, the resultant solution was filtered to wipe out sediment and further precipitated by mixed solution (acetone: ethyl ether $=3: 7$ ). After the obtained sediment was washed by ethyl ether for several times and further vacuum dried, FA active ester was obtained.

In the next step, $1 \mathrm{~g}$ gelatin was dissolved in $100 \mathrm{~mL}$ PBS to obtain $1 \%$ gelatin solution, into which $8 \mathrm{~mL}$ FA-active ester DMSO solution was added drop by drop in $1 \mathrm{~h}$. After the reaction had lasted for $12 \mathrm{~h}$ at $40^{\circ} \mathrm{C}$, the resultant solution was sealed in a dialysis bag with a cutoff molecular weight of $10 \mathrm{kDa}$ and dialyzed in a large amount of triple-distilled water for $3 \mathrm{~d}$. Finally, gelation-folic acid ester (G-FA) was obtained by freeze drying and characterized by nuclear magnetic resonance hydrogen spectrum $\left(_{1} \mathrm{H}\right.$ NMR, BRUKER AV500). The structure of G-FA was shown in Figure 1(b). The degree of substitution (DS) for G-FA was calculated by the area of ${ }_{1} \mathrm{H}$ NMR. In addition, G-FA water solution and FA solution with equal FA content were characterized by spectrofluorometer (FS5). The fluorescence intensity as a function of G-FA concentration was also tracked using the same measuring parameter.

2.3. Fabrication and Characterization of the FA Functional pH-Responsive Nanoparticle. In order to prepare the nanoparticle, acetylated $\beta$-cyclodextrin (Ac- $\beta$-CD) was first synthesized using the previous method [33]. Briefly, $1 \mathrm{~mol}$ 2-methoxypropene was dropped into $500 \mathrm{~mL} 50 \mathrm{mM}$ $\beta$-CD/anhydrous DMSO solution containing $5 \mathrm{mM}$ pyridinium p-toluene sulfonate in an anhydrous anaerobic environment. After the reaction had lasted for $1 \mathrm{~h}$ at $30^{\circ} \mathrm{C}$, 


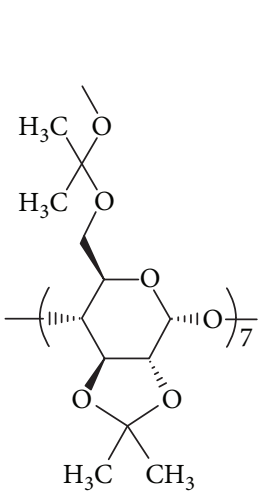

(a)

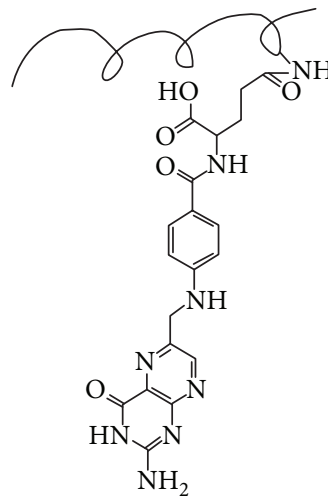

(b)

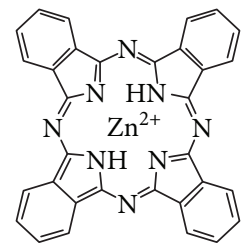

(c)

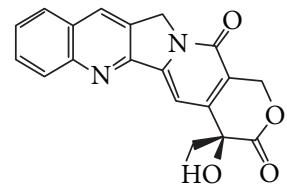

(d)

Figure 1: The chemical or schematic structure of (a) Ac- $\beta$-CD, (b) G-FA, (c) PcZn, and (d) CPT.

Ac- $\beta$-CD was precipitated from basic water, collected by filtration, and lastly lyophilized to white powder. The structure of Ac- $\beta$-CD was shown in Figure 1(a).

FA functional $\mathrm{pH}$-responsive nanoparticles were prepared by a similar microemulsion method as mentioned in a previous research [33]. But differently, G-FA was used as a functional emulsifier. Briefly, $10 \%$ Ac- $\beta$-CD/DCM solution was emulsified via probe sonication (Scientz, JY92-II) into 3\% G-FA aqueous solution. The obtained emulsion was immediately added into $1 \%$ concentration G-FA aqueous solution to evaporate DCM under magnetic stirring. After $10 \mathrm{~h}$, nanoparticles were collected by centrifugation (14000 rpm, $10 \mathrm{~min}$ ), washed several times with basic water, and lyophilized. The lyophilized nanoparticles were used for further characterization. G-FA solution after separation could be dialyzed for purification and lyophilized for recycling. The final nanoparticles were characterized by Fourier-transformed infrared spectroscopy (FTIR) (IS10), scanning electron microscope (SEM) (S8100), and spectrofluorometer (FS5). In characterization, nanoparticles were dispersed in alkaline water to form nanoparticle solution, which was further dropped onto an aluminum film and dried by an infrared lamp. Then the sample was coated with $\mathrm{Pt}$, which was further observed under SEM. The fluorescence intensity of acid nanoparticle dissolved solution was determined to quantify the G-FA content on the nanoparticle surface, which was calculated by the abovementioned calibration curve in the last section.

2.4. Cell Endocytosis of the Nanoparticle. The nanoparticle was marked with rhodamine isocyanate. Briefly, nanoparticles were dispersed in $0.1 \mathrm{mg} / \mathrm{mL}$ rhodamine isocyanate alkaline solution ( $\mathrm{pH} 7.5$ ). After the reaction had lasted for $24 \mathrm{~h}$, nanoparticles were washed several times, lastly lyophilized, and sterilized before use.

The cell endocytosis profile was evaluated by coculture of the nanoparticle and adherent cells. Briefly, HEP2 cells were incubated in a humidified atmosphere of $95 \%$ air and 5\% $\mathrm{CO}_{2}$ at $37^{\circ} \mathrm{C}$. The used cells were detached by $0.25 \%$ trypsin, washed by PBS, and resuspended by culture medium with a cell density of 50-100 cells $/ \mu \mathrm{L}$. Then the resuspended cells were seeded on one 12-well culture plate and several $3.5 \mathrm{~cm}$ culture dishes with embedded glass slides. After cells were fused by about $40-60 \%$ on each well (approximately $24 \mathrm{~h}$ ), original culture medium was discarded and fresh culture medium containing the nanoparticle as a function of nanoparticle concentration was supplemented. For different intervals, cells on each well of the culture plate were detached and detected by flow cytometry (FCM, BD, C6) using cells without the nanoparticle as a gate. At the same time, cells on dishes were fixed by $2.5 \%$ glutaraldehyde, stained by $0.1 \mu \mathrm{g} / \mathrm{mL}$ DAPI for $20 \mathrm{~min}$, washed by PBS three times, sealed by antifade mounting medium, and finally observed in a fluorescence microscope (IX73). Theoretically, DAPI was a fluorescent dye, which could penetrate cell membrane and react with double-chain DNA. After reaction, DAPI-DNA could produce blue fluorescence 20 times higher than DAPI itself.

2.5. In Vitro Evaluation for the Drug-Encapsulated Nanoparticle. PcZn (Figure 1(c)) and CPT (Figure 1(d)) were chosen as model drugs to be encapsulated into the abovementioned nanoparticle during the process of nanoparticle fabrication. Briefly, $100 \mu \mathrm{L}$ CPT/DMSO solution of different concentrations was mixed with $10 \%$ Ac- $\beta$-CD/DCM solution containing saturated PcZn, which was further emulsified via probe sonication into G-FA aqueous solution, just as mentioned above. Final drug-encapsulated nanoparticles were obtained using the same abovementioned method.

PcZn/DCM, PcZn/water solution, and nanoparticle suspension were characterized by spectrofluorometer (FS5). The fluorescence intensity of nanoparticle suspension in different media as a function of time was recorded by spectrofluorometer (FS5). Quantification of CPT was accomplished by ultraviolet spectrophotometric method using UV spectroscopy (Cary 50). In order to qualify the encapsulated CPT amount, nanoparticle suspension was dialyzed in $15 \mathrm{~mL} 1 \mathrm{mM} \mathrm{HCL}$ solution to dissolve all nanoparticles. The encapsulated CPT amount was obtained by absorbance of HCL dialysis solution and calculation according to the standard curve. For CPT release assay, nanoparticle suspension was dialyzed in $15 \mathrm{~mL}$ water solution with different $\mathrm{pH}$ values. At appropriate intervals, $3 \mathrm{~mL}$ released dialysis solution was withdrawn and the absorbance at $360 \mathrm{~nm}$ was 


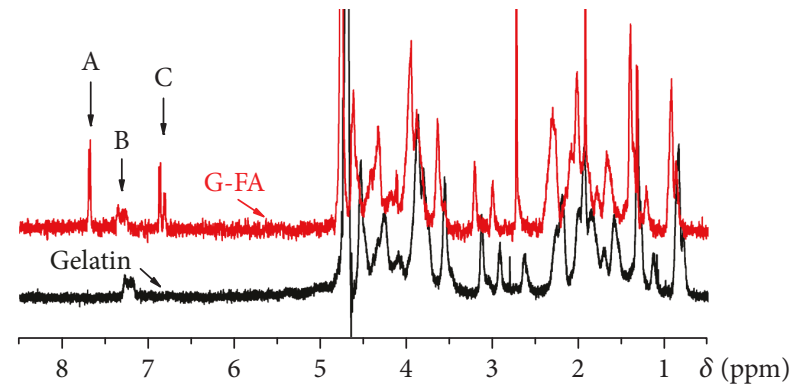

(a)

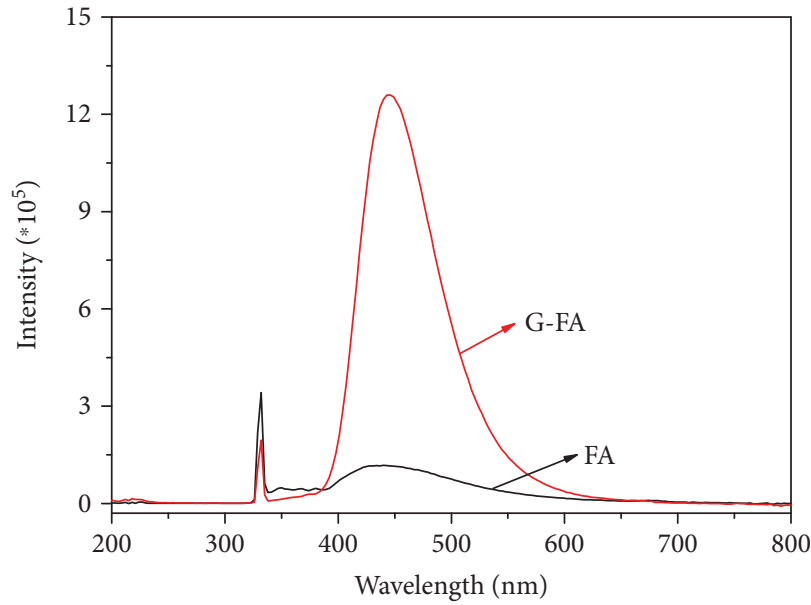

(b)

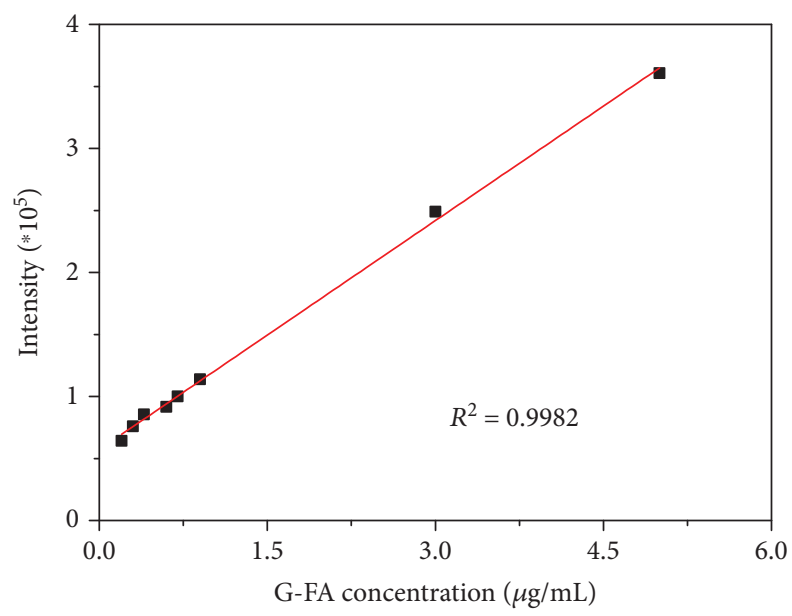

(c)

Figure 2: (a) ${ }_{1} \mathrm{H}$ NMR spectra of gelatin and G-FA. (b) Fluorescence spectra of FA and G-FA water solution with an excitation wavelength of $336 \mathrm{~nm}$. (c) Fluorescence intensity of G-FA water solution as a function of G-FA concentration.

recorded to calculate the cumulate $\mathrm{CPT}$ release. Simultaneously, $3 \mathrm{~mL}$ fresh solution was supplemented into dialysis solution.

Besides the in vitro drug release profile, effects of drug-encapsulated nanoparticles on viability of HEP2 cells were evaluated by MTT assay. Briefly, nanoparticle DMEM solution with different nanoparticle concentrations was added into a 96-well culture plate with $80-90 \%$ cell confluence. At different intervals, after being supplemented with $20 \mu \mathrm{L} \mathrm{MTT}$, the cells were continually cultured for another $4 \mathrm{~h}$. $200 \mu \mathrm{L}$ of DMSO was added to dissolve the formed formazan pigment. The absorbance of $150 \mu \mathrm{L}$ above solution at $570 \mathrm{~nm}$ was recorded by a microplate reader (Tecan M200 PRO).

2.6. In Vivo Evaluation. All the animal experimental protocols were performed in compliance with the Animal Management Rules of the Ministry of Health of the People's Republic of China (no. 55, 2001) and the guidelines for the Care and Use of Laboratory Animals of the Nanjing University of Chinese Medicine (Nanjing, China). The protocol was approved by the Jiangsu Experimental Animal Committee. The protocol used was also approved by the Ethics Committee of Nanjing University. HEP2 tumor-bearing nude mice were used to give a preliminary assessment of the drugencapsulated nanoparticles. The mice were divided into a nanoparticle-treated group $(40 \mathrm{mg} / \mathrm{kg})$ and treated with normal saline (the control group, $n=5$ per group). The sample was intravenously injected via tail vein every day. Tumor size and animal body weight were measured every day during the study, and the tumor volume was calculated by the formula $\left(\right.$ width $^{2} \times$ length $) / 2$. After 12 days, animals were sacrificed to the experiment under the institutional guideline and the tumor tissue was fixed by glutaraldehyde, embedded in paraffin, and cut into $5 \mu \mathrm{m}$ slices. The slice was dewaxed with xylene, washed with various levels of ethanol and water, and further stained by hematoxylin-eosin (H-E). Finally, the slide was dehydrated, sealed, and characterized by a microscope (IX73).

2.7. Statistical Analysis. Data were analyzed using the $t$-test for differences. Results are reported as means \pm standard deviation. The significant level was set at $p<0.05$. 


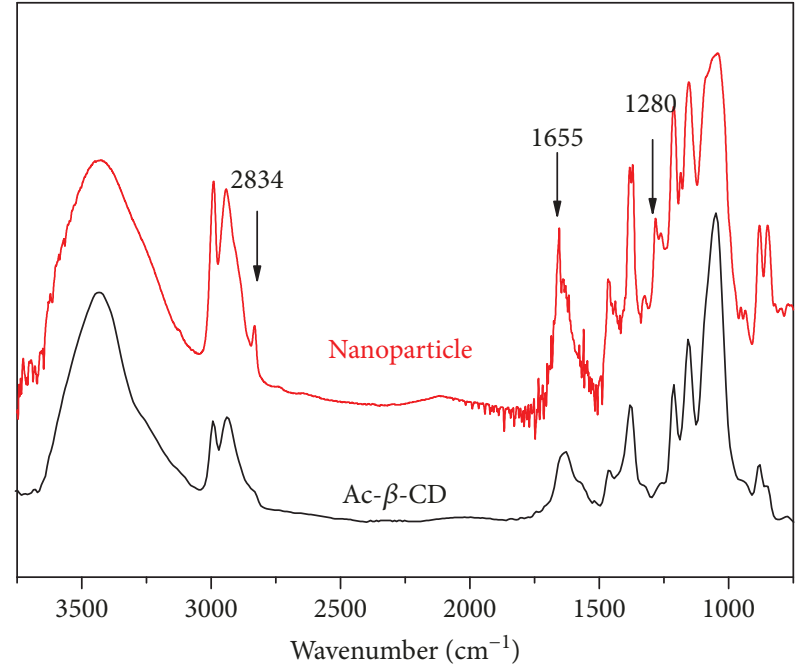

(a)

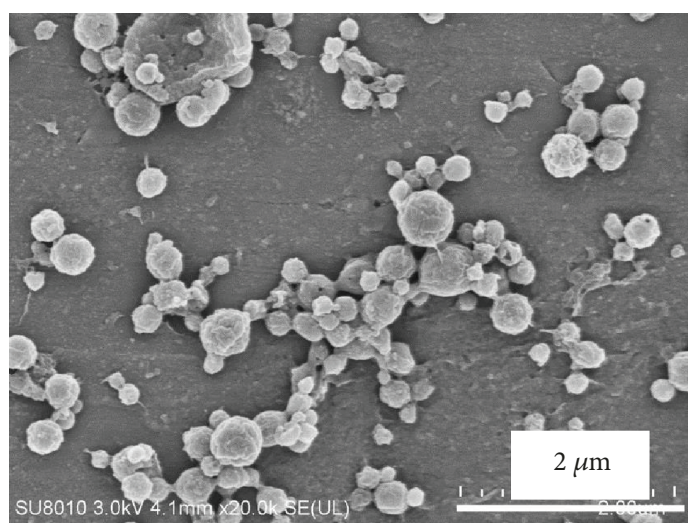

(b)

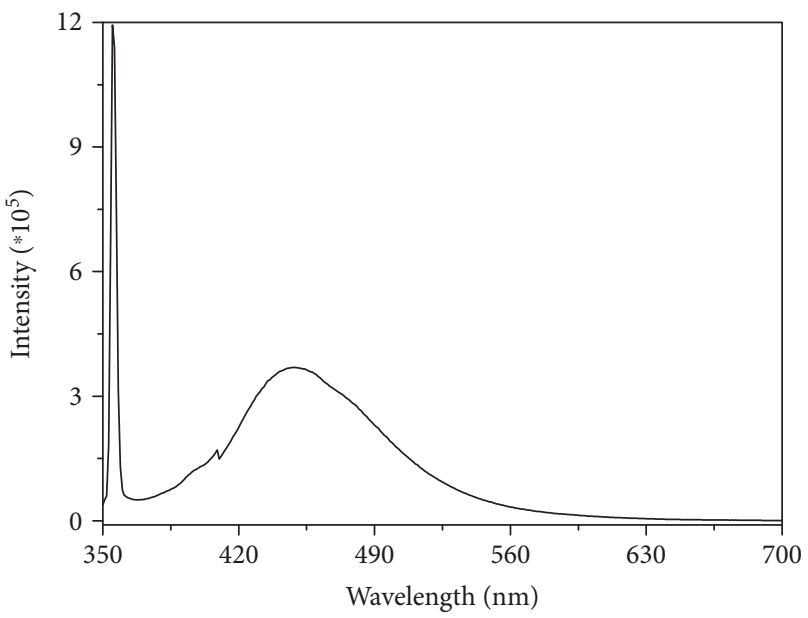

(c)

FIgure 3: (a) FTIR spectra of Ac- $\beta$-CD and G-FA functional nanoparticles. (b) SEM images of the G-FA functional nanoparticle. (c) Fluorescence spectrum of the G-FA functional nanoparticle.

\section{Result and Discussion}

3.1. Synthesis and Characterization of G-FA. In order to obtain the FA functional nanoparticle, FA was first grafted onto gelatin, an emulgator by amidation reaction. ${ }_{1} \mathrm{H}$ NMR spectra provided detailed structural information of gelatin before and after modification, which was shown in Figure 2(a). The peaks are assigned as follows: a peak of $0.86 \mathrm{ppm}$ belonging to the methyl residues of leucine, valine, and isoleucine; peaks of 1.16, 1.36, 1.61, and $1.72 \mathrm{ppm}$ belonging to the methyl residues of threonine, alanine, lysine, and arginine, respectively; peaks of 2.64, $2.93,3.14$, and $3.57 \mathrm{ppm}$ belonging to methylene residues of aspartic acid, lysine, arginine, and proline, respectively; peaks of 7.04-7.20 ppm belonging to the phenyl group of phenylalanine (b position); and peaks of 6.86 and $7.67 \mathrm{ppm}$ belonging to the phenyl group of FA ( $a$ and $c$ position). The emergence of groups belonging to FA confirmed the successful grafting of FA onto the gelatin chain. In addition, the grafting ratio of FA was calculated by integration of peaks a and $b$, considering that one gelatin molecule has 60 phenylalanine groups and 32 lysine groups containing $\mathrm{NH}_{2}$, which was $94 \%$.

The fluorescence spectra of FA and G-FA water solution were detected to clarify the fluorescence property for G-FA in Figure 2(b). Excited by $336 \mathrm{~nm}$ fluorescence, FA solution showed an emission peak with small intensity at $455 \mathrm{~nm}$ but equal G-FA solution showed an emission peak with high intensity nearly ten times as high as that of FA, which indicated that gelatin enhanced the fluorescence property of FA. The enhancement of protein on the fluorescence property for FA had been confirmed by previous reports, which was consistent with our results [42]. Furthermore, fluorescence intensity of G-FA at $455 \mathrm{~nm}$ as a function of its concentration was recorded in Figure 2(c). It was found that when G-FA concentration is at $0.2-5.0 \mu \mathrm{g} / \mathrm{mL}$, fluorescence intensity of G-FA had a good linear relationship with G-FA concentration, which could be used to quantify the G-FA content in the following part. 


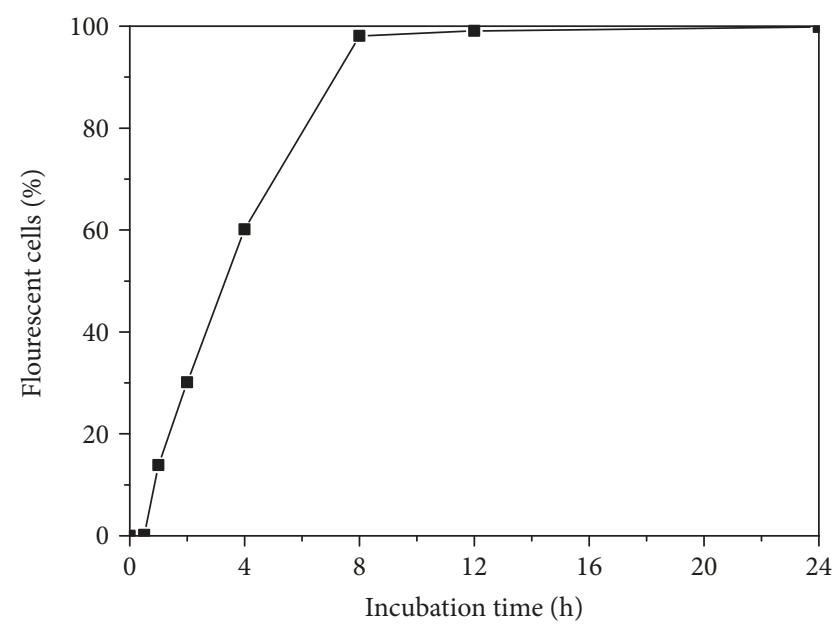

(a)

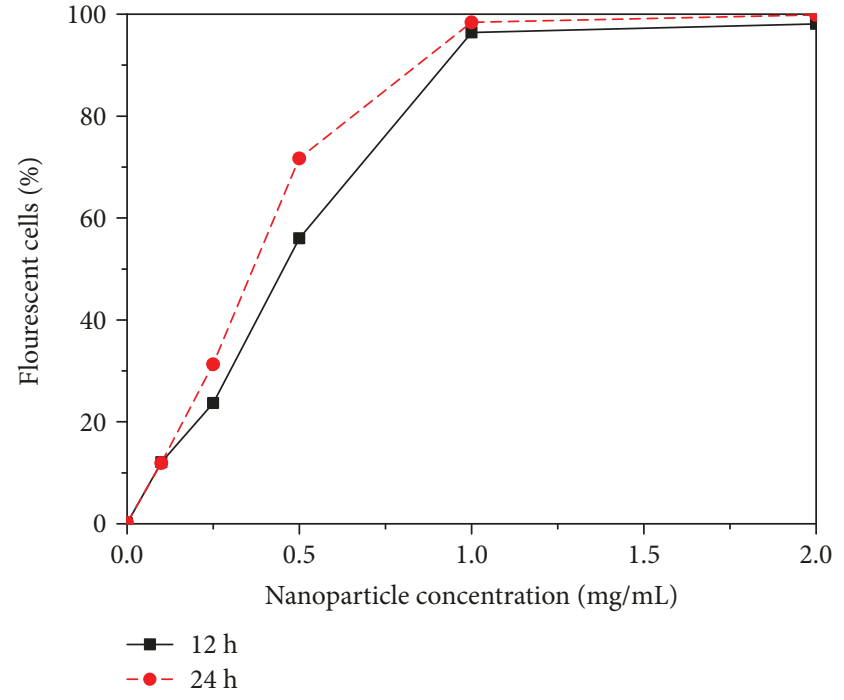

(b)

FIGURE 4: Fluorescent HEP2 cell percentage as a function of incubation time incubated with the $2 \mathrm{mg} / \mathrm{mL}$ RBITC-labeled nanoparticle (a) and as a function of RBITC-labeled nanoparticle concentration incubated for $12 \mathrm{~h}$ and $24 \mathrm{~h}(\mathrm{~b})$.

3.2. FA Functional pH-Responsive Nanoparticle. Since detailed information of Ac- $\beta$-CD had been researched and discussed in our previous research, the synthesis and characteristic of Ac- $\beta$-CD were not discussed here.

It was found in our previous research that the emulgator was inevitably absorbed onto the surface of the nanoparticle. Therefore, a FA functional emulgator, namely, G-FA, was expected to obtain the FA functional nanoparticle surface in nanoparticle fabrication. In order to clarify the surface characteristic, the obtained nanoparticle and its precursor of Ac- $\beta$-CD were characterized by FTIR spectra (Figure $3(\mathrm{a})$ ). Compared with the spectrum of Ac- $\beta$-CD, appearance of peaks at $2834 \mathrm{~cm}^{-1}$ and $1280 \mathrm{~cm}^{-1}$ belonging to carboxylic acid or amino groups of gelatin or FA and obvious enhancement of peak at $1655 \mathrm{~cm}^{-1}$ belonging to amide characteristic groups of G-FA confirmed the existence of G-FA on the surface of the nanoparticle, which is consistent with our previous report [33].

The formed G-FA functional $\mathrm{pH}$-responsive nanoparticle showed a coarse surface with a diameter of about 100-300 nm from SEM images (Figure 2(b)), which was similar to a previously prepared Ac- $\beta$-CD nanoparticle [33]. Although some aggregation was witnessed in a dried state, homogeneous nanoparticle solution with a defined effective diameter of about $250 \mathrm{~nm}$ (PDI: 0.149) was confirmed by DLS results.

Furthermore, a fluorescence spectrum of nanoparticle solution was detected in Figure 2(c). Excited by $336 \mathrm{~nm}$ fluorescence, nanoparticle solution showed an emission peak with small intensity at $455 \mathrm{~nm}$, which confirmed the existence of G-FA on the surface of the nanoparticle. The G-FA content on the nanoparticle surface was quantified by fluorescence intensity of acid-dissolved nanoparticle solution and calculated to be $1.04 \pm 0.29 \mathrm{mg} / \mathrm{g}$ by referring Figure 2(c).
Additionally, it was found from transparency of nanoparticle solution that the nanoparticle could stably exist in PBS (pH 7.2-7.4) for 10 days, gradually degrade in pure water ( $\mathrm{pH}$ 6.0-6.5) within 2 days, and rapidly dissolve in mild acid solution ( $\mathrm{pH}$ 5.0-5.5) within 2 hours. The result confirmed the $\mathrm{pH}$-responsive properties of the nanoparticle and was consistent with the previous research [33].

3.3. Cell Endocytosis of the Nanoparticle. In order to track cell endocytosis of the nanoparticle, nanoparticles were labeled with a fluorescence dye (RBITC) and further cocultured with adherent HEP2 cells. It was found from the FCM result in Figure 4 that the number fraction of fluorescent cells increased rapidly with cocultured time until $8 \mathrm{~h}$ (Figure 4(a)) and increased rapidly with nanoparticle concentration until it reached $1.0 \mathrm{mg} / \mathrm{mL}$ (Figure 4(b)). Intelligibly, cells would have fluorescence if they endocytosed fluorescent nanoparticles, that is, fluorescent cells were considered to the cells that endocytosed the nanoparticle. Therefore, FCM results confirmed the successful cell endocytosis for nanoparticles and the endocytosis reached equilibrium for the $1.0 \mathrm{mg} / \mathrm{mL}$ nanoparticle and after $8 \mathrm{~h}$.

Furthermore, cell endocytosis behavior was observed by a fluorescence microscope, in which cell nucleus was stained to blue color and the nanoparticle showed red color (Figure 5). In one aspect, after being cocultured for $24 \mathrm{~h}$, without the nanoparticle, only blue nucleus could be observed in the fluorescence image (Figure 5(a)); with the nanoparticle, the red nanoparticle could be observed to distribute around the nucleus or inside the nucleus (Figures 5(b)-5(e)). But no obvious linear relationship between the red nanoparticle amount and cocultured nanoparticle concentration was found in these fluorescent images. In other aspects, with $0.5 \mathrm{mg} / \mathrm{mL}$ nanoparticles, a few nanoparticles were scattered inside the cells (either 


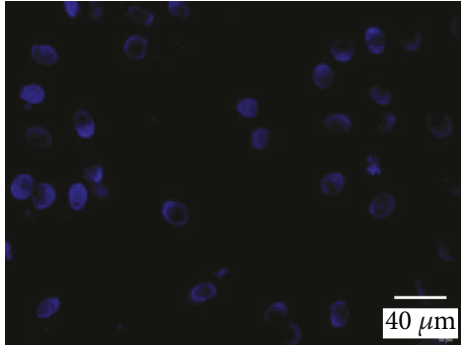

(a)

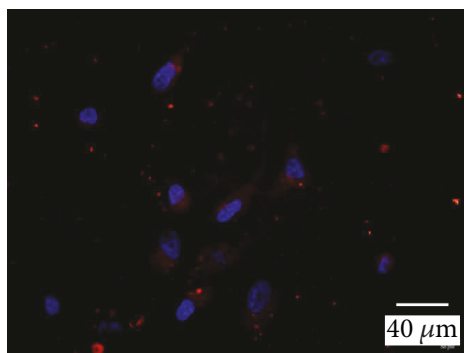

(c)

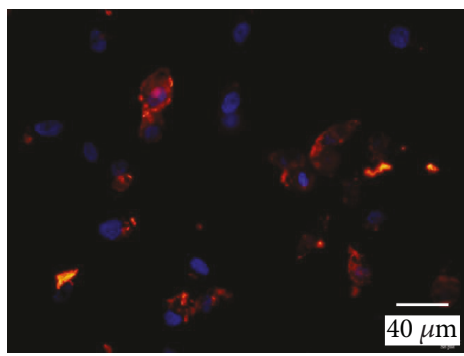

(e)

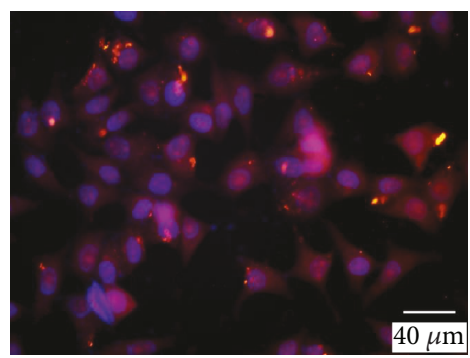

(g)

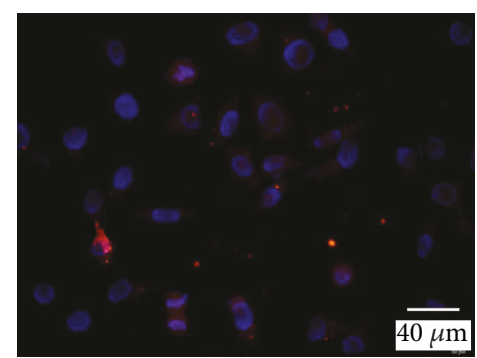

(b)

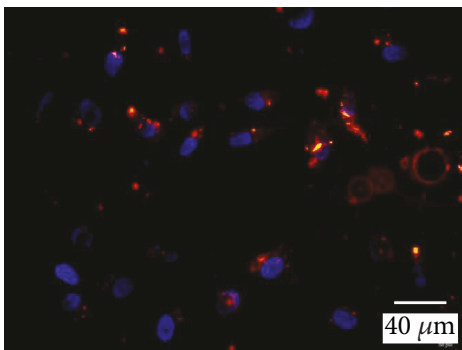

(d)

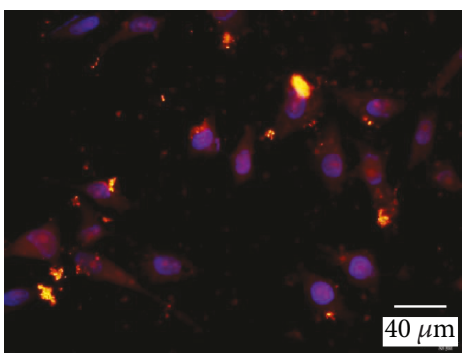

(f)

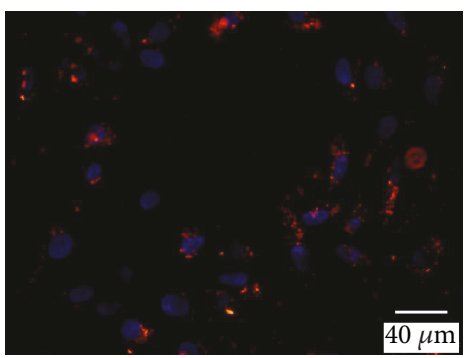

(h)

Figure 5: HEP2 cells stained by DAPI and observed by fluorescence microscopy after the cells were cocultured with RBITC-labeled nanoparticles for different coculture time ( $\mathrm{d}, \mathrm{f}, \mathrm{g}$, and $\mathrm{h}$ ) and different nanoparticle concentrations ( $\mathrm{a}, \mathrm{b}, \mathrm{c}, \mathrm{d}$, and e). In detail, cocultured with (a) $0 \mathrm{mg} / \mathrm{mL}$ nanoparticle for $24 \mathrm{~h}$, (b) $0.1 \mathrm{mg} / \mathrm{mL}$ nanoparticle for $24 \mathrm{~h}$, (c) $0.25 \mathrm{mg} / \mathrm{mL}$ nanoparticle for $24 \mathrm{~h}$, (d) $0.5 \mathrm{mg} / \mathrm{mL}$ nanoparticle for $24 \mathrm{~h}$, (e) $1 \mathrm{mg} / \mathrm{mL}$ nanoparticle for $24 \mathrm{~h}$, (f) $0.5 \mathrm{mg} / \mathrm{mL}$ nanoparticle for $2 \mathrm{~h},(\mathrm{~g}) 0.5 \mathrm{mg} / \mathrm{mL}$ nanoparticle for $6 \mathrm{~h}$, and (h) $0.5 \mathrm{mg} / \mathrm{mL}$ nanoparticle for $12 \mathrm{~h}$.

inside the nucleus or inside the cytomembrane) after $2 \mathrm{~h}$; further, the nanoparticle number seemed to increase a lot inside the cells and nearly all nucleuses were surrounded by many nanoparticles after $6 \mathrm{~h}$. Surprisingly, the nanoparticle amount inside the cells decreased after $12 \mathrm{~h}$ and $24 \mathrm{~h}$, which might be ascribed to dissolution of the nanoparticle inside the cells or exocytosis by cell. In view of no obvious exocytosis phenomenon from FCM results, degradation of the nanoparticle might be a main reason for the nanoparticle reduction after $12 \mathrm{~h}$.
In brief, these results of the cell endocytosis profile indicated that the nanocarrier could realize the intracellular delivery of drugs.

3.4. In Vitro Evaluation. On account of slight solubility, PcZn in water solution was difficult to be quantified by spectroscopy. Thus, the fluorescence characteristic of PcZn solution was qualitatively tracked in Figure 6. Excited by $355 \mathrm{~nm}$ fluorescence, PcZn-saturated DCM solution exhibited a maximal emission peak with a fluorescence intensity of $7.5^{*} 10^{7}$ at 


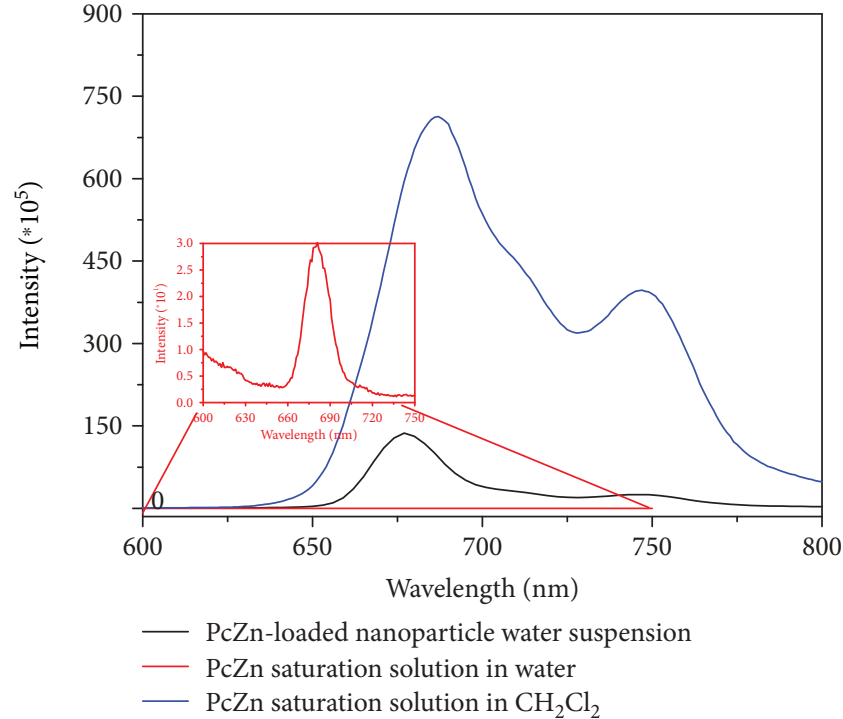

(a)

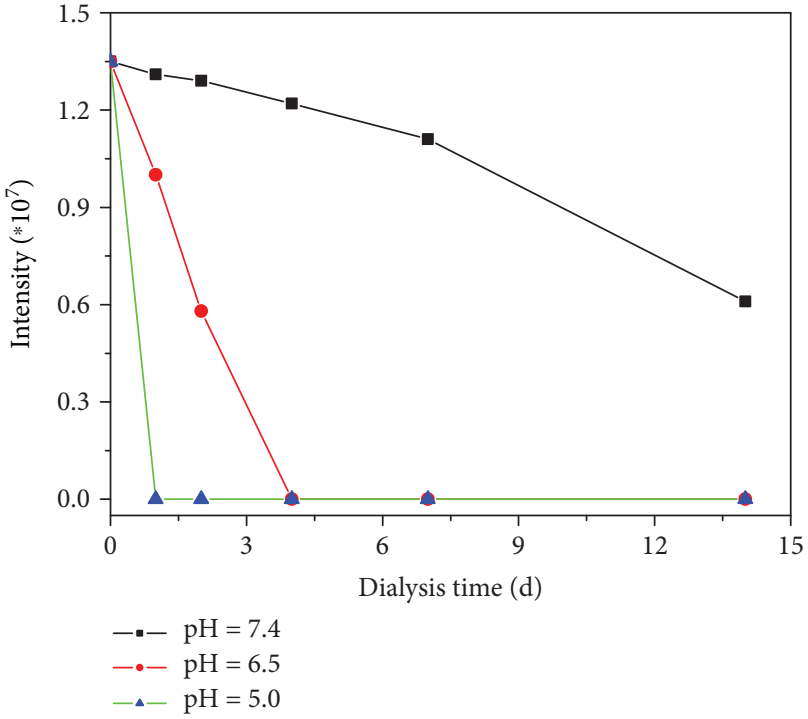

(b)

Figure 6: (a) Fluorescence spectra of PcZn encapsulation nanoparticle water suspension, PcZn saturation water solution, and PcZn saturation $\mathrm{CH}_{2} \mathrm{Cl}_{2}$ solution. (b) Fluorescence intensity of $\mathrm{PcZn}$ encapsulation nanoparticle water suspension in different media as a function of dialysis time.

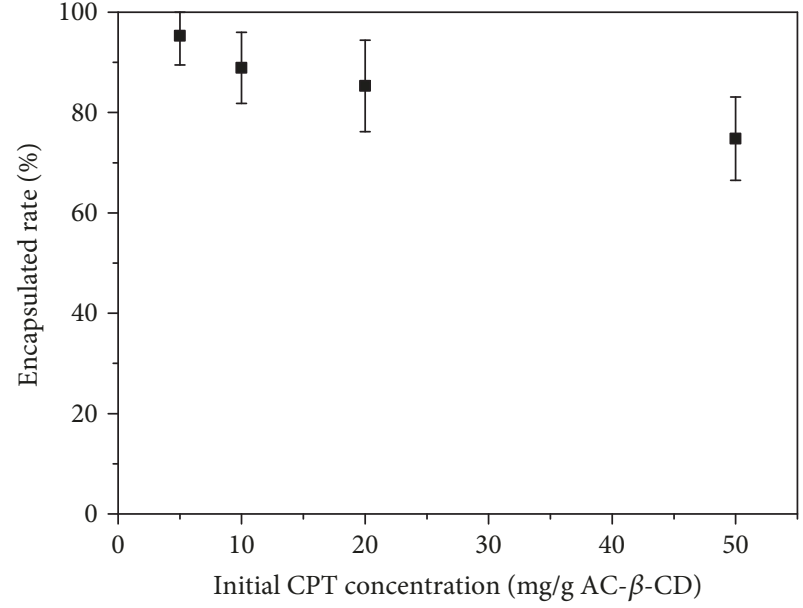

(a)

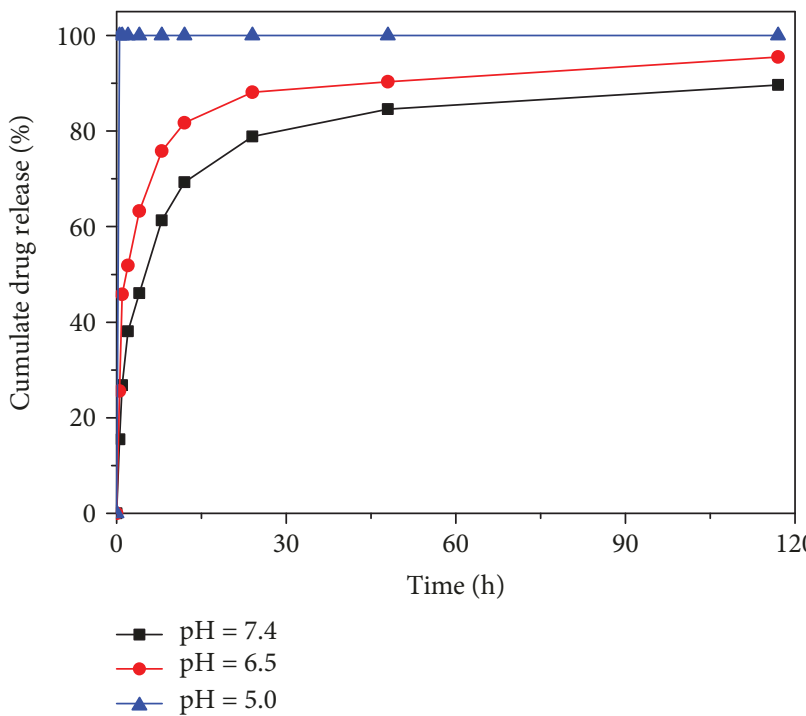

(b)

FIGURE 7: (a) CPT encapsulation efficiency in the nanoparticle with different initial CPT concentrations. (b) In vitro cumulate CPT release behaviors in different $\mathrm{pH}$ value media at $37^{\circ} \mathrm{C}$.

$670 \mathrm{~nm}$ (Figure 6(a)). However, the fluorescence intensity at $670 \mathrm{~nm}$ for PcZn-saturated water solution decreased to $3.0^{*}$ $10^{3}$ on account of insolubility and aggregation in water, which would hinder the absorbance of light energy and then reduce curative effects (Figure 6(a)). Interestingly, nanoparticle suspension showed the same emission peak with a fluorescence intensity of $1.5^{*} 10^{7}$, which indicated that the nanoparticle could enhance fluorescence effects of PcZn due to better dispersibility in water. In order to track the stability of the PcZn encapsulation nanoparticle in water, fluorescence intensity of nanoparticle water suspension in different media as a function of time was recorded in Figure 6(b). In a neutral environment (PBS, pH 7.4), fluorescence intensity of nanoparticle suspension gradually decreased along time within 2 weeks; in mild acid solution ( $\mathrm{pH}$ 5.0), fluorescence intensity rapidly reduced to very low in a day; in water, the nanoparticle lost majority of their fluorescence in 4 days. The gradual decline of fluorescence intensity is assumed to be attributed to gradual diffusion of PcZn into solution since the nanoparticle had been verified to be stable in PBS and PcZn had very low fluorescence intensity; quick loss of the fluorescence property for the 


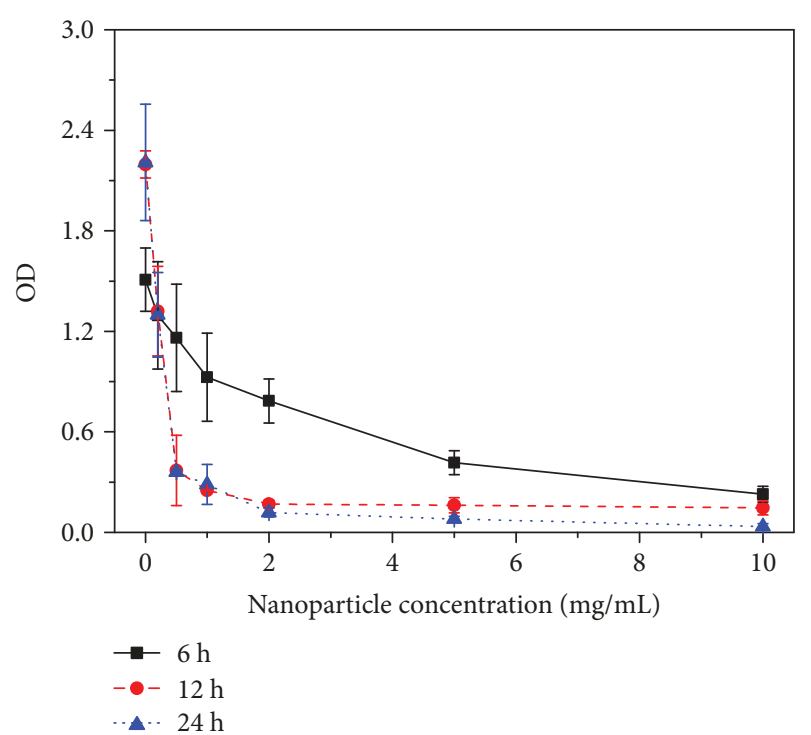

Figure 8: Optical density of HEP2 cells as a function of nanoparticle concentration after cultured in different time and incubated with MTT.

nanoparticle in a mild acid environment is ascribed to the degradation of the nanoparticle and aggregation of PcZn in solution.

Differently, quantification of CPT was accomplished by spectroscopy, which was shown in Figure 7. It was found that the CPT encapsulation rate decreased slightly along with initial CPT concentration increasing (Figure $7(\mathrm{a})$ ). Since CPT did not dissolve in $\mathrm{DCM}$, a higher $\mathrm{CPT} / \mathrm{Ac}-\beta$ - $\mathrm{CD}$ ratio might influence the homogeneity of the CPT/Ac- $\beta$-CD mixture and stability of nanoparticle-prepared emulsion, which resulted in a lower encapsulated CPT rate. In the drug release profile (Figure 7(b)), 80\% encapsulated CPT was gradually released to PBS (pH 7.4) within $24 \mathrm{~h}, 90 \%$ encapsulated CPT was gradually released to water ( $\mathrm{pH} 6.5$ ) within $24 \mathrm{~h}$, and nearly $100 \%$ encapsulated CPT was burst released to acid medium ( $\mathrm{pH}$ 5.0) within the first hour. In view of the degradation rate of the nanoparticle in different media, the release of CPT in PBS was mainly driven by molecular diffusion for CPT, while burst CPT was attributed to quick degradation of the nanoparticle in an acid environment.

To sum up, relative temporary stability of either drug or photosensitizer in a normal physiological environment ( $\mathrm{pH} 7.4)$ and burst release in a mild acid environment ( $\mathrm{pH}$ 5.0) ensured effective delivery of the drug and photosensitizer to targeted tissue and did limited harm to normal tissue.

Moreover, since $\mathrm{CPT}$ and $\mathrm{ZnPc}$ have been proven to have reduced curative effects due to slight solubility and G-FA had no cytotoxicity according to common sense and our experiment, cytoviability of only the nanocarrier had been examined. In vitro effects of the nanocarrier on HEP2 cells were investigated in Figure 8. After coculture for 6 h, cytoviability decreased with the increase of nanoparticle concentration until nanoparticle concentration reached $5 \mathrm{mg} / \mathrm{mL}$. After coculture for $12 \mathrm{~h}$ or $24 \mathrm{~h}$, cytoviability decreased rapidly with the increase of nanoparticle concentration until nanoparticle concentration reached $2 \mathrm{mg} / \mathrm{mL}$. Many dead cells confirmed the effectiveness and efficiency of nanocarriers on HEP2 cells.

3.5. Preliminary In Vivo Evaluation. The curative effect of the nanocarrier was preliminary evaluated by tumor's volume and body weight of nude mice in Figure 9. In the research, only a common cancer model (bearing cancer) under the skin with a short-term test was used to give a preliminary evaluation for multifunctional nanocarriers. The tumor's volume kept its original size along with time within 12 days for the treatment group, while the tumor's volume kept increasing along with time within 12 days for the control group (Figure 9(a)). Especially after 6 days, the tumor's volume of the treatment group was significant smaller than that of the control group, which indicated that the nanocarrier could inhibit the growth of tumor. Although the error bar of the tumor volume was big due to mobility and uncontrollability of bearing tumor for the control group, the error bar of the tumor volume was much smaller for the treatment group. Obvious tumor development was found in the control group along with time, while no obvious tumor development was found in the treatment group along with time. It was inferred that imbalance of tumor development coming from biological individual differences was also the reason for the big error bar. In other aspects, the mouse's weight kept constant along with time either for the treatment group or for the control group (Figure 9(b)) and no obvious difference for the mouse's weight between the treatment group and the control group was detected, which inferred that the nanocarrier had little influence on conventional life activities of mice. After 12 days, tumor tissue was sectioned and stained by H\&E in Figures 9(c) and 9(d). For the treatment group, some tissue frame without obvious cell nucleus was observed in the image (Figure 9(c)), which might be attributed to the death of cancer cells. Besides this, some relative smaller blue nucleus in the image might be a sign of cellular apoptosis. As a contrast, many normal cancer cells were observed in the image for the control group, except some blank region (Figure 9(d)). In a word, the results of preliminary in vivo evaluation showed that the nanocarrier could inhibit cancer development.

To sum up, the characteristic of intracellular delivery from in vitro cell endocytosis results indicated that the nanocarrier would induce the delivered drug to targeted tissues even cells. Simultaneously the nanocarrier could encapsulate both drug and photosensitizer to some extent and adjust their release according to the component-structure characteristic of the nanocarrier. These characteristics ensured more effective and efficient targeted molecule delivery. Preliminary in vivo evaluation further verified the cancer inhabitation effect for the nanocarrier. These results exhibited bright prospects for the nanocarrier in their potential biomedical application.

\section{Conclusion}

FA functional emulgator, namely, G-FA, was successfully synthesized with DS of $94 \%$. The synthesized G-FA exhibited 


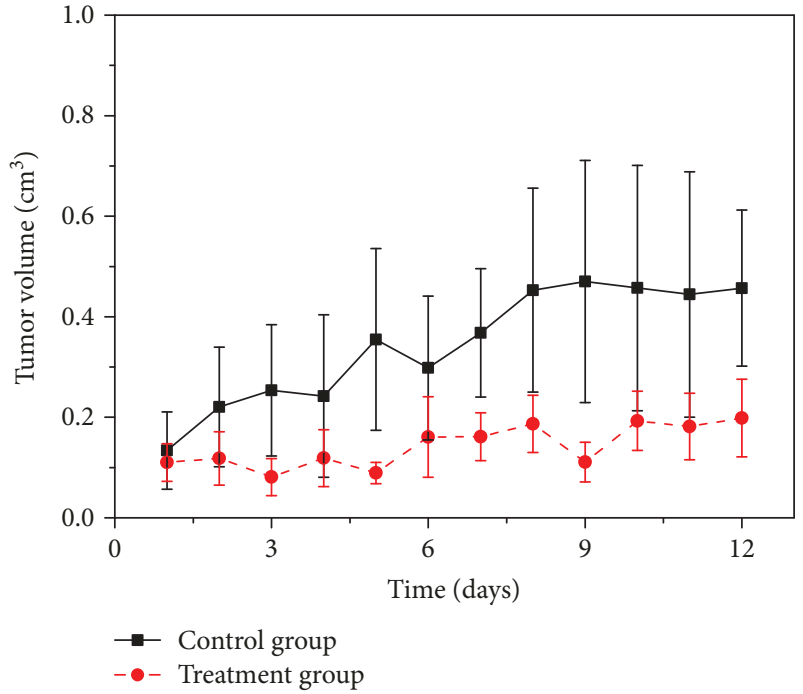

(a)

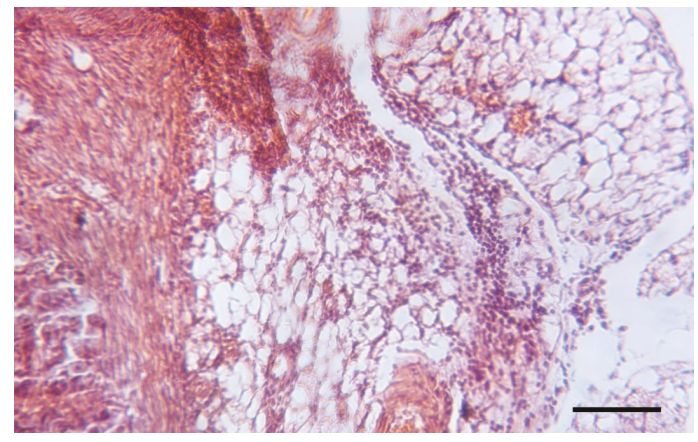

(c)

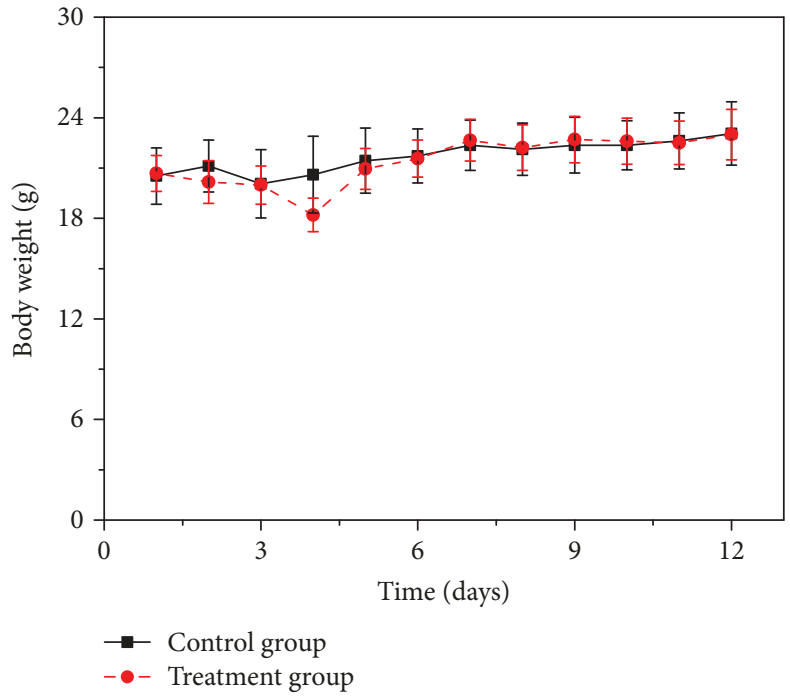

(b)

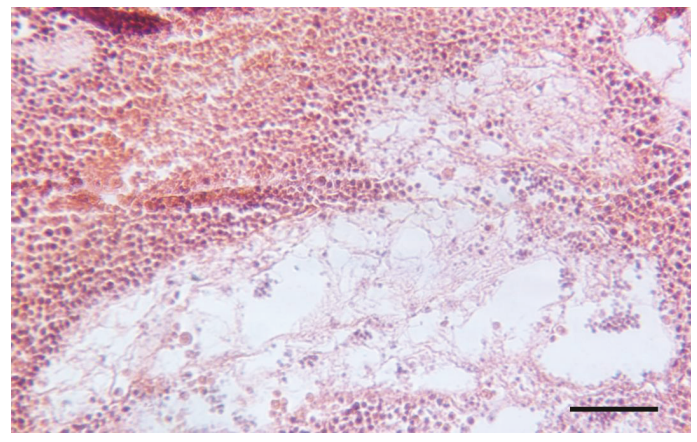

(d)

Figure 9: (a) Tumor volume of a nude mouse as a function of treatment time, (b) body weight of a nude mouse as a function of treatment time, (c) H\&E-stained sections of tumor from mice sacrificed 12 days after treatment, and (d) H\&E-stained sections of tumor from mice sacrificed 12 days without treatment. The scale is $100 \mu \mathrm{m}$.

enhanced fluorescence property and good linear intensity-concentration correlation. The G-FA functional $\mathrm{pH}$-responsive nanoparticle with a G-FA content of $1.04 \pm$ $0.29 \mathrm{mg} / \mathrm{g}$ was successfully prepared by emulsion method. The formed nanoparticle showed a coarse surface with a diameter of about $100-300 \mathrm{~nm}$, pH-responsive property, and similar fluorescence property to G-FA. The nanoparticle could be successfully endocytosed by cells. Equilibrium endocytosis could be reached after $8 \mathrm{~h}$ with $1.0 \mathrm{mg} / \mathrm{mL}$ nanoparticle. Moreover, degradation of the nanoparticle might be involved in cell endocytosis process. Anticancer drug (CPT) and photosensitizer (PcZn) could be encapsulated in the nanoparticle. The nanoparticle enhanced the fluorescence effects of PcZn on water solution, and the CPT encapsulation rate decreased slightly along with initial CPT concentration increasing. A gradual decline of fluorescence intensity for the PcZn encapsulation nanoparticle in PBS solution and a quick loss of fluorescence intensity in mild acid solution were witnessed by a fluorescence spectrum. Similarly, gradual CPT release in PBS within $24 \mathrm{~h}$ and burst release in acid medium within the first hour were detected. In vitro cytoviability evaluation showed that the nanocarrier could decrease viability of HEP2 cells to a very low value. The results of preliminary in vivo evaluation revealed that the nanocarrier could inhibit cancer development with little effects on the body weight of mice. In conclusion, these results indicated that the nanoparticle with a pH-responsive property and targeted characteristic was an effective and efficient nanocarrier for codelivery of anticancer drug and photosensitizer.

\section{Data Availability}

The data used to support the findings of this study are included within the article.

\section{Conflicts of Interest}

The authors declare that there is no conflict of interests regarding the research.

\section{Authors' Contributions}

Xiaohong Hu and Ziyu Gao contributed equally to this work and should be considered co-first authors. 


\section{Acknowledgments}

This study was financially supported by the Natural Science Foundation of Jiangsu Province (BK20171113) and Qing Lan Project, Six Talent Peaks Project in Jiangsu Province (JY-071). We thank Mr. Yong Bian and the animal centre of Nanjing University of Chinese Medicine for the animal experiment.

\section{References}

[1] T. Wang, L. Zhang, Z. Su, C. Wang, Y. Liao, and Q. Fu, "Multifunctional hollow mesoporous silica nanocages for cancer cell detection and the combined chemotherapy and photodynamic therapy," ACS Applied Materials \& Interfaces, vol. 3, no. 7, pp. 2479-2486, 2011.

[2] C. He, D. Liu, and W. Lin, "Self-assembled core-shell nanoparticles for combined chemotherapy and photodynamic therapy of resistant head and neck cancers," ACS Nano, vol. 9, no. 1, pp. 991-1003, 2015.

[3] Z. Wang, R. Ma, L. Yan, X. Chen, and G. Zhu, "Combined chemotherapy and photodynamic therapy using a nanohybrid based on layered double hydroxides to conquer cisplatin resistance," Chemical Communications, vol. 51, no. 58, pp. 11587-11590, 2015.

[4] F. Suzuki, M. Misawa, H. Sugimura, S. Yamawaki, and M. Aoshima, "Efficacy of photodynamic therapy combined with a guide sheath method concomitant with chemotherapy in a small-cell lung cancer patient with central endobronchial stenosis," Photodiagnosis and Photodynamic Therapy, vol. 16, pp. 169-171, 2016.

[5] Y. F. Ding, S. Li, L. Liang et al., "Highly biocompatible chlorin e6-loaded chitosan nanoparticles for improved photodynamic cancer therapy," ACS Applied Materials \& Interfaces, vol. 10, no. 12, pp. 9980-9987, 2018.

[6] X. Zhuang, X. Ma, X. Xue et al., "A photosensitizer-loaded DNA origami nanosystem for photodynamic therapy," ACS Nano, vol. 10, no. 3, pp. 3486-3495, 2016.

[7] A. G. Cheetham, P. Zhang, Y. A. Lin, L. L. Lock, and H. Cui, "Supramolecular nanostructures formed by anticancer drug assembly," Journal of the American Chemical Society, vol. 135, no. 8, pp. 2907-2910, 2013.

[8] L. Meng, W. Huang, D. Wang, X. Huang, X. Zhu, and D. Yan, "Chitosan-based nanocarriers with $\mathrm{pH}$ and light dual response for anticancer drug delivery," Biomacromolecules, vol. 14, no. 8, pp. 2601-2610, 2013.

[9] X. Chen, X. Ling, L. Zhao et al., "Biomimetic shells endow sub-50 $\mathrm{nm}$ nanoparticles with ultrahigh paclitaxel payloads for specific and robust chemotherapy," ACS Applied Materials \& Interfaces, vol. 10, no. 40, pp. 33976-33985, 2018.

[10] J. Wang, W. Xu, S. Li et al., "Polylactide-cholesterol stereocomplex micelle encapsulating chemotherapeutic agent for improved antitumor efficacy and safety," Journal of Biomedical Nanotechnology, vol. 14, no. 12, pp. 2102-2113, 2018.

[11] J. Chen, J. Ding, Y. Wang et al., "Sequentially responsive shell-stacked nanoparticles for deep penetration into solid tumors," Advanced Materials, vol. 29, no. 32, article 1701170, 2017.

[12] W. Zhang, J. Shen, H. Su et al., "Co-delivery of cisplatin prodrug and chlorin e6 by mesoporous silica nanoparticles for chemo-photodynamic combination therapy to combat drug resistance," ACS Applied Materials \& Interfaces, vol. 8, no. 21 , pp. 13332-13340, 2016.

[13] W. Miao, G. Shim, S. Lee, S. Lee, Y. S. Choe, and Y. K. Oh, "Safety and tumor tissue accumulation of pegylated graphene oxide nanosheets for co-delivery of anticancer drug and photosensitizer," Biomaterials, vol. 34, no. 13, pp. 3402-3410, 2013.

[14] X. L. Wu, J. H. Kim, H. Koo et al., “Tumor-targeting peptide conjugated $\mathrm{pH}$-responsive micelles as a potential drug carrier for cancer therapy," Bioconjugate Chemistry, vol. 21, no. 2, pp. 208-213, 2010.

[15] J. Liang, W. L. Wu, X. D. Xu, R. X. Zhuo, and X. Z. Zhang, "pH responsive micelle self-assembled from a new amphiphilic peptide as anti-tumor drug carrier," Colloids and Surfaces. B, Biointerfaces, vol. 114, pp. 398-403, 2014.

[16] S. Lu, W. F. Bennett, Y. Ding et al., "Design and characterization of a multifunctional $\mathrm{pH}$-triggered peptide $\mathrm{C} 8$ for selective anticancer activity," Advanced Healthcare Materials, vol. 4, no. 17, pp. 2709-2718, 2015.

[17] R. Salehi, S. Rasouli, and H. Hamishehkar, "Smart thermo/pH responsive magnetic nanogels for the simultaneous delivery of doxorubicin and methotrexate," International Journal of Pharmaceutics, vol. 487, no. 1-2, pp. 274-284, 2015.

[18] Z. Guo, J. Chen, L. Lin et al., "pH triggered size increasing gene carrier for efficient tumor accumulation and excellent antitumor effect," ACS Applied Materials \& Interfaces, vol. 9, no. 18, pp. 15297-15306, 2017.

[19] H. L. Ramirez, A. Valdivia, R. Cao, J. J. Torres-Labandeira, A. Fragoso, and R. Villalonga, "Cyclodextrin-grafted polysaccharides as supramolecular carrier systems for naproxen," Bioorganic \& Medicinal Chemistry Letters, vol. 16, no. 6, pp. 1499-1501, 2006.

[20] J. Jo, A. Okazaki, K. Nagane, M. Yamamoto, and Y. Tabata, "Preparation of cationized polysaccharides as gene transfection carrier for bone marrow-derived mesenchymal stem cells," Journal of Biomaterials Science. Polymer Edition, vol. 21, no. 2, pp. 185-204, 2010.

[21] Y. Ohyabu, H. Hatayama, and S. Yunoki, "Evaluation of gelatin hydrogel as a potential carrier for cell transportation," Journal of Bioscience and Bioengineering, vol. 118, no. 1, pp. 112-115, 2014.

[22] V. Singh and S. Ahmad, "Carboxymethyl cellulose-gelatin-silica nanohybrid: an efficient carrier matrix for alpha amylase," International Journal of Biological Macromolecules, vol. 67, pp. 439-445, 2014.

[23] Z. Ren, Y. Wang, S. Ma et al., "Effective bone regeneration using thermosensitive poly( $\mathrm{N}$-isopropylacrylamide) grafted gelatin as injectable carrier for bone mesenchymal stem cells," ACS Applied Materials \& Interfaces, vol. 7, no. 34, pp. 1900619015, 2015.

[24] X. H. Hu and X. Gong, "A new route to fabricate biocompatible hydrogels with controlled drug delivery behavior," Journal of Colloid and Interface Science, vol. 470, pp. 62-70, 2016.

[25] X. H. Hu, H. P. Tan, and L. Y. Hao, "Functional hydrogel contact lens for drug delivery in the application of oculopathy therapy," Journal of the Mechanical Behavior of Biomedical Materials, vol. 64, pp. 43-52, 2016.

[26] X. H. Hu, H. P. Tan, X. Wang, and P. Chen, "Surface functionalization of hydrogel by thiol-yne click chemistry for drug delivery," Colloids and Surfaces A: Physicochemical and Engineering Aspects, vol. 489, pp. 297-304, 2016. 
[27] K. E. Broaders, J. A. Cohen, T. T. Beaudette, E. M. Bachelder, and J. M. Frechet, "Acetalated dextran is a chemically and biologically tunable material for particulate immunotherapy," Proceedings of the National Academy of Sciences of the United States of America, vol. 106, no. 14, pp. 5497-5502, 2009.

[28] H. M. Borteh, M. D. Gallovic, S. Sharma et al., "Electrospun acetalated dextran scaffolds for temporal release of therapeutics," Langmuir, vol. 29, no. 25, pp. 7957-7965, 2013.

[29] K. V. Hoang, H. M. Borteh, M. V. Rajaram et al., "Acetalated dextran encapsulated AR-12 as a host-directed therapy to control Salmonella infection," International Journal of Pharmaceutics, vol. 477, no. 1-2, pp. 334-343, 2014.

[30] N. Chen, M. A. Collier, M. D. Gallovic et al., "Degradation of acetalated dextran can be broadly tuned based on cyclic acetal coverage and molecular weight," International Journal of Pharmaceutics, vol. 512, no. 1, pp. 147-157, 2016.

[31] M. A. Collier, K. J. Peine, S. Gautam et al., "Host-mediated Leishmania donovani treatment using AR-12 encapsulated in acetalated dextran microparticles," International Journal of Pharmaceutics, vol. 499, no. 1-2, pp. 186-194, 2016.

[32] E. M. Bachelder, E. N. Pino, and K. M. Ainslie, “Acetalated dextran: a tunable and acid-labile biopolymer with facile synthesis and a range of applications," Chemical Reviews, vol. 117, no. 3, pp. 1915-1926, 2017.

[33] X. H. Hu, S. N. Chen, X. Gong, Z. Y. Gao, X. Wang, and P. Chen, "Synthesis and preparation of biocompatible and pH-responsive cyclodextrin-based nanoparticle," Journal of Nanoparticle Research, vol. 19, no. 3, 2017.

[34] F. Danhier, O. Feron, and V. Preat, "To exploit the tumor microenvironment: passive and active tumor targeting of nanocarriers for anti-cancer drug delivery," Journal of Controlled Release, vol. 148, no. 2, pp. 135-146, 2010.

[35] N. T. Huynh, E. Roger, N. Lautram, J. P. Benoit, and C. Passirani, "The rise and rise of stealth nanocarriers for cancer therapy: passive versus active targeting," Nanomedicine, vol. 5, no. 9, pp. 1415-1433, 2010.

[36] N. Bertrand, J. Wu, X. Xu, N. Kamaly, and O. C. Farokhzad, "Cancer nanotechnology: the impact of passive and active targeting in the era of modern cancer biology," Advanced Drug Delivery Reviews, vol. 66, pp. 2-25, 2014.

[37] R. Bazak, M. Houri, S. El Achy, S. Kamel, and T. Refaat, "Cancer active targeting by nanoparticles: a comprehensive review of literature," Journal of Cancer Research and Clinical Oncology, vol. 141, no. 5, pp. 769-784, 2015.

[38] Y. Zhao, H. Chen, X. Chen et al., “Targeted nanoparticles for head and neck cancers: overview and perspectives," Wiley Interdisciplinary Reviews. Nanomedicine and Nanobiotechnology, vol. 9, no. 6, 2017.

[39] R. I. Pinhassi, Y. G. Assaraf, S. Farber et al., "Arabinogalactan-folic acid-drug conjugate for targeted delivery and target-activated release of anticancer drugs to folate receptor-overexpressing cells," Biomacromolecules, vol. 11, no. 1, pp. 294-303, 2010.

[40] I. Naharci, E. Bozoglu, N. Karadurmus et al., "Vitamin B(12) and folic acid levels as therapeutic target in preserving bone mineral density (BMD) of older men," Archives of Gerontology and Geriatrics, vol. 54, no. 3, pp. 469-472, 2012.
[41] Y. Huang, K. Mao, B. Zhang, and Y. Zhao, "Superparamagnetic iron oxide nanoparticles conjugated with folic acid for dual target-specific drug delivery and MRI in cancer theranostics," Materials Science and Engineering: C, vol. 70, Part 1, pp. 763-771, 2017.

[42] R. L. Merzel, C. Frey, J. Chen et al., "Conjugation dependent interaction of folic acid with folate binding protein," Bioconjugate Chemistry, vol. 28, no. 9, pp. 2350-2360, 2017. 


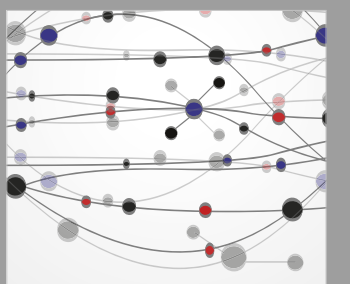

The Scientific World Journal
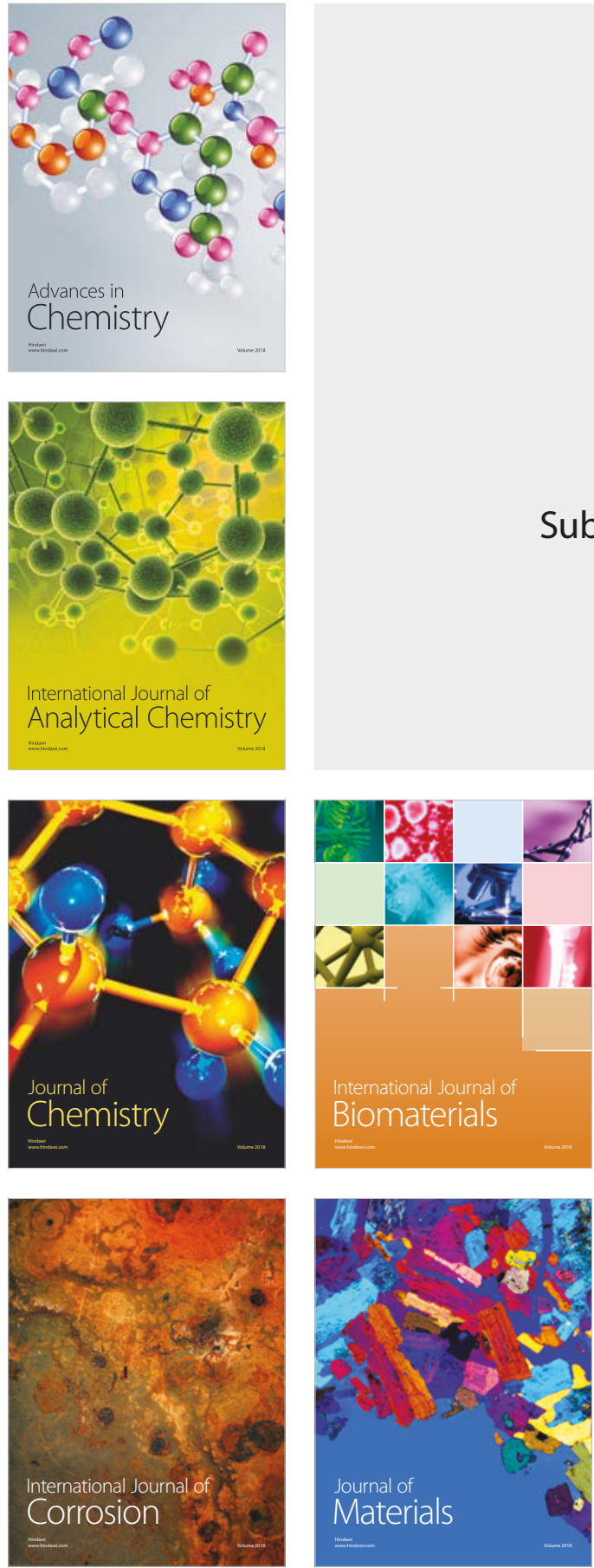

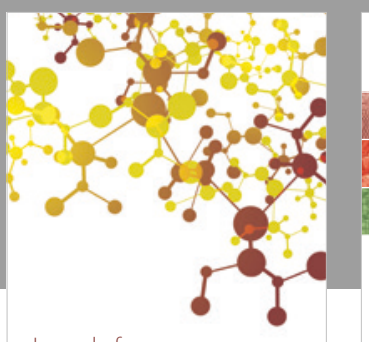

Journal of

Applied Chemistry
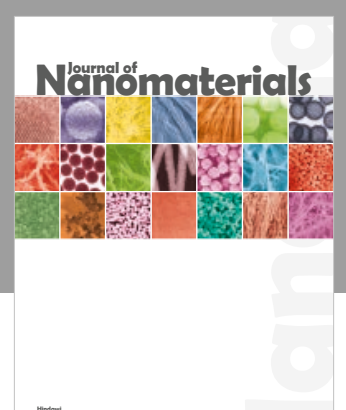

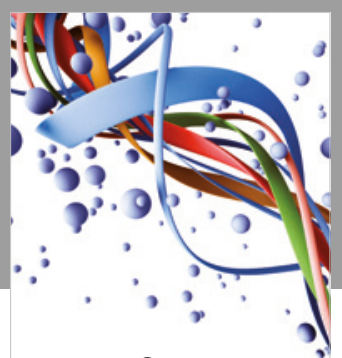

Scientifica

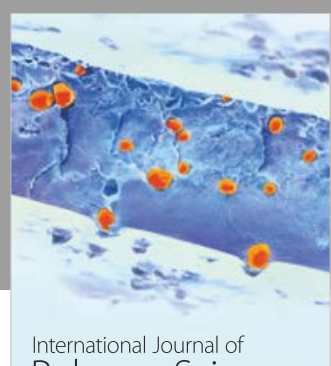

Polymer Science

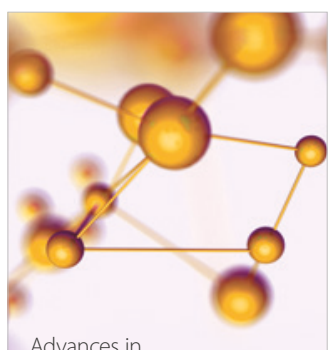

Physical Chemistry
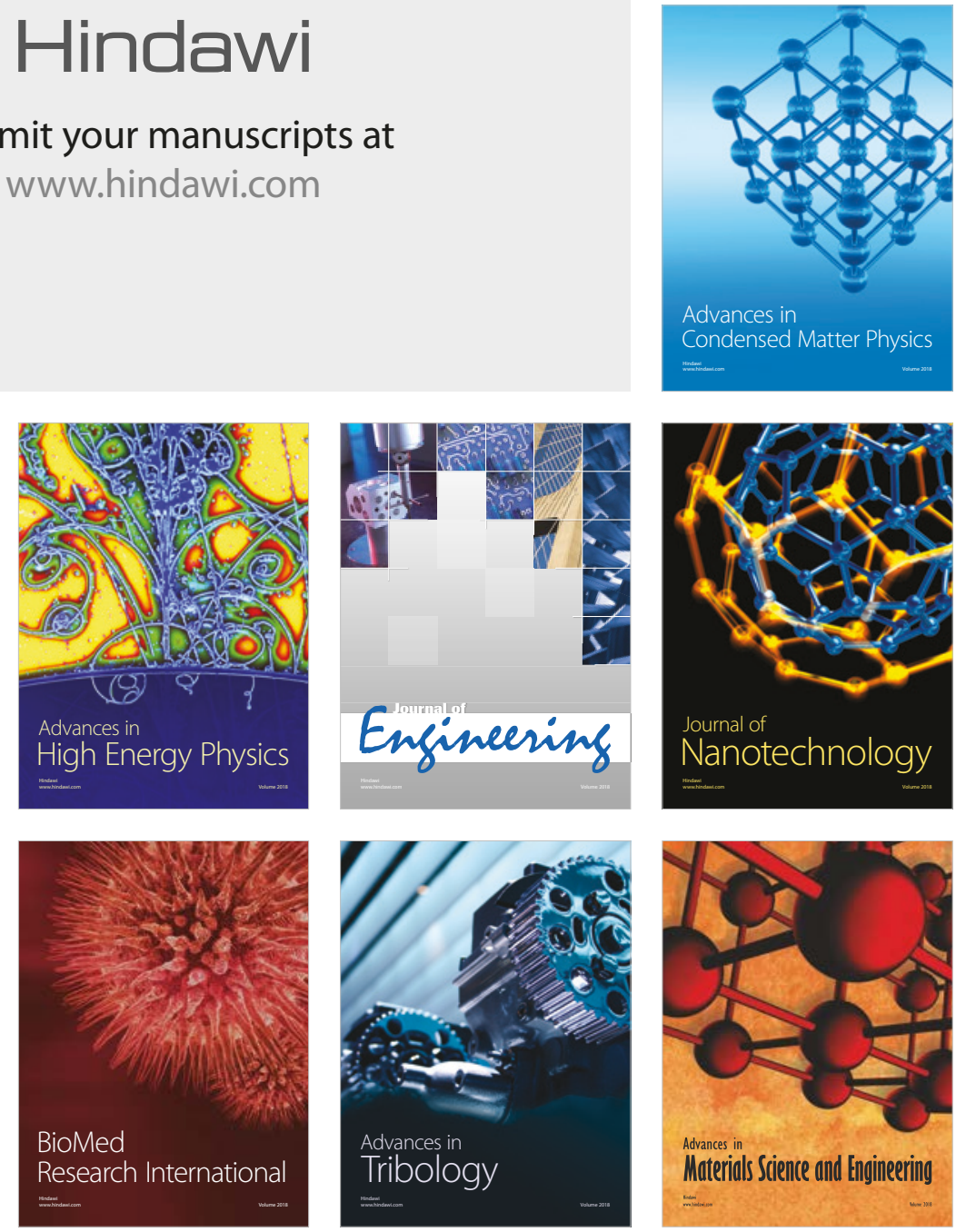